\title{
The creative process in architectural design on a digital environment: an experience with beginner students
}

\section{SIGRADI2018 TECHNOPOLITICAS \\ xxii congresso da sociedade iberoamericana de gráfica digital 22th conference of the iberoamerican society of digital graphics 07|08|09|novembro|2018 iauusp| são carlos| spbr}

\author{
Sérgio Dias Maciel \\ UNEMAT / UFBA | Brazil | sdmac@terra.com.br
}

Arivaldo Leão De Amorim
UFBA | Brazil | alamorim@ufba.br

Érica De Souza Checcucci

UFBA | Brazil | erica.checcucci@ufba.br

Kyane Bomfim Santos

UFBA | Brazil | kyanebomfim@gmail.com

\begin{abstract}
This article presents some results in the architectural design course, which were obtained by under graduate students in two experimental class organized at Federal University of Bahia in 2016 and 2017 years. The class Studio I, with incoming students (2016) and Integrated Digital Studio, with beginners and sophomore students (2017), were planned to have their activities developed in a digital environment, using geometric modeling as the main resource for the architectural design. The results obtained show maturity and autonomy of the students related to architectural designing and the use of digital resources.
\end{abstract}

Keywords: Architectural design; Architectural design teaching; Geometric Modeling; CAAD.

\section{INTRODUÇÃO}

Segundo Broadbent (1973) e Rowe (1991) é comum que os arquitetos utilizem métodos heurísticos na projetação, seguindo desde princípios simples (método pragmático) aos mais sofisticados (método canônico), além da utilização de analogias. Para Mitchell (2010), a projetação pode depender de um vocabulário gráfico pertencente ou disponibilizado ao arquiteto, que pode ser empregado segundo critérios específicos do mesmo, criando mundos projetuais. Para Lawson (2011) a projetação depende de um conjunto de restrições, rígidas ou flexíveis, podendo ser geradas pelo cliente, pelo poder público e pelo próprio arquiteto, sendo que a utilização das restrições ou de parte delas, pode determinar o fio condutor da solução, ou seja, servir como gerador primário da proposta projetual.

A projetação objetiva uma formalização espacial que, segundo Silva (1998) e Mahfuz (1995) é definida como partido arquitetônico e esse é apresentado nos cursos de graduação em arquitetura e urbanismo já nos momentos iniciais da formação do estudante.

Silva (1998) descreve a importância da transparência no percurso para o partido arquitetônico, onde as etapas que o antecedem são fundamentadas e organizadas, valorizando as informações e as relações funcionais entre os espaços. Sob outro enfoque, Mahfuz (1995) destaca as relações topológicas entre as partes ou as formas que definem o partido arquitetônico adotado.

O partido arquitetônico responde espacialmente aos problemas que motivaram o projeto e a ordenação de seus elementos podem ser compreendidos como uma estruturação do processo criativo, conforme Ostrower (2014). No ensino, o partido arquitetônico pode determinar a relevância do resultado conseguido pelo aluno no seu contexto, sendo que em muitas situações, pode apresentar elementos que sejam uma novidade para si ou para os demais, conforme Bodem (1999).

Dessa forma, o objetivo desse artigo é apresentar os resultados da projetação arquitetônica desenvolvida diretamente no computador por alunos: (a) de primeiro ano, das turmas de Ateliê I (ARQ016) em 2016 e, (b) de primeiro e segundo anos, em uma turma mista no Ateliê Digital Integrado, que une alunos do Ateliê I (ARQ016) e do Ateliê II (ARQ024), no ano de 2017, na Universidade Federal da Bahia.

Dentre as questões que serão discutidas, podem ser ressaltadas: Houve dificuldades com a utilização dos recursos digitais? Quais recursos podem ser utilizados? Como deve ser o processo pedagógico para ensino e aprendizagem de projeto utilizando recursos computacionais? Os resultados alcançados podem ser considerados satisfatórios?

As experiências realizadas nos anos de 2016 e 2017 partem do pressuposto que a projetação e o ambiente digital podem ser integrados desde as séries iniciais da formação do estudante de arquitetura, permitindo que este experimente formas diferenciadas na concepção do projeto, fundamentando suas propostas projetuais e utilizando recursos variados de software e hardware, 
ampliando o conhecimento e acelerando a formação do seu repertório.

No processo de ensino realizado em ambiente digital é essencial fornecer ferramentas de fácil manuseio e aprendizagem aos estudantes, de forma que eles consigam definir com desenvoltura o partido arquitetônico, evitando que eles sejam limitados pela falta de recursos ou pela usabilidade da ferramenta empregada.

Sobre este aspecto, foi observado que o software adotado nas disciplinas possui uma curva de aprendizagem adequada, mas apresenta poucos recursos para modelagem de formas complexas, enquanto programas que se adequam melhor a esses tipos de formas são mais difíceis de aprender e manipular. Por outro lado, o estudante iniciante as vezes deseja adotar uma forma não convencional, entretanto ele ainda possui a maturidade para a viabilização da mesma.

Diante disto, a escolha do software é um fator decisivo, pois deve garantir a usabilidade e a fluidez necessárias às fases iniciais da projetação.

\section{METODOLOGIA}

Foi proposta no ano letivo de 2016, uma turma da disciplina Ateliê I, no Curso de Graduação em Arquitetura e Urbanismo da FAUFBA, com objetivo de introduzir a projetação arquitetônica em ambiente digital, de modo que todas as atividades fossem realizadas com esses recursos, substituindo a abordagem clássica de ensino de projeto baseada em desenhos técnicos por uma fundamentada na representação digital.

A principal ferramenta adotada foi o SketchUp Make, sendo que para o seu aprendizado foi oferecida uma oficina com doze horas-aula de duração, com objetivo de passar os conhecimentos iniciais sobre a modelagem geométrica e a organização das informações do modelo. Ao mesmo tempo, foram apresentados os conteúdos da representação arquitetônica e o processo para obtenção dos desenhos técnicos em escala, a partir do modelo geométrico. Por fim, foi apresentado o processo de organização dos desenhos nas pranchas utilizando o software Inkscape.

Os conteúdos inerentes ao processo projetual, como: a explicitação do processo e suas restrições; o programa de necessidades; o pré-dimensionamento; 0 partido arquitetônico; elementos construtivos como estruturas, cobertura e vedações, foram apresentados no decorrer do curso, à medida que foram sendo necessários. Nesse caso, o procedimento adotado teve por objetivo dotar a projetação de transparência, conforme Silva (1998).

Ainda no ano letivo de 2016, foram realizados sete exercícios projetuais com grau crescente de dificuldade, em aproximadamente oito meses de aulas. Todas as atividades de projeto seguiram a mesma rotina: realização de pesquisas iniciais para subsidiar a proposta, desenvolvimento do programa, pré-dimensionamento dos espaços, funcionograma e fluxograma, zoneamento e estudo de massas, criação do partido arquitetônico e desenvolvimento do estudo preliminar da proposta. Esta etapa era sempre apresentada e discutida em sala por todo o grupo de alunos e professores. Em uma segunda etapa, os alunos entregavam as pranchas impressas.

A disciplina foi realizada no LCAD e contou com uma equipe de dois professores, um professor em estágio docente e três monitores que se revezaram durante o período letivo.

Da mesma forma, no ano letivo de 2017, foi proposto o Ateliê Digital Integrado, composto por uma turma de alunos ingressantes (Ateliê I) e outra turma (Ateliê II) com alunos aprovados nas turmas oferecidas em 2016. A turma Ateliê Digital Integrado seguiu os mesmos princípios metodológicos que a turma Ateliê I (2016), onde foram realizados seis projetos na nova turma Ateliê I e seis projetos na turma Ateliê II.

O Quadro 1 mostra os exercícios projetuais desenvolvidos em 2016 e 2017, sendo que as atividades dos Ateliês I (2016 e 2017) foram realizadas em nível de estudo preliminar e as atividades do Ateliê II (2017) foram realizadas em nível de anteprojeto.

\begin{tabular}{|c|c|c|c|c|}
\hline \multicolumn{5}{|c|}{ Atividades de projeto } \\
\hline \multirow[t]{2}{*}{ At. } & \multirow{2}{*}{$\begin{array}{l}\text { Ateliê I } \\
\text { (2016) }\end{array}$} & \multirow[t]{2}{*}{ At. } & \multicolumn{2}{|c|}{ Ateliê Digital Integrado (2017) } \\
\hline & & & Ateliê I & Ateliê II \\
\hline 1 & $\begin{array}{c}\text { Mobiliário } \\
\text { urbano }\end{array}$ & 1 & $\begin{array}{c}\text { Mobiliário } \\
\text { urbano }\end{array}$ & $\begin{array}{c}\text { Residência } \\
\text { universitária }\end{array}$ \\
\hline 2 & Galpão & 2 & Praça & $\begin{array}{l}\text { Atividade } \\
\text { Tema livre }\end{array}$ \\
\hline 3 & Praça & 3 & Galpão & Escola \\
\hline \multicolumn{5}{|c|}{ Recesso entre os semestres } \\
\hline 4 & Residência & 4 & Residência & $\begin{array}{c}\text { Diagnóstico } \\
\text { urbano }\end{array}$ \\
\hline 5 & $\begin{array}{c}\text { Centro } \\
\text { comercial }\end{array}$ & 5 & $\begin{array}{r}\text { Edifício } \\
\text { (Exercício con }\end{array}$ & $\begin{array}{l}\text { o misto } \\
\text { das } 2 \text { turmas) }\end{array}$ \\
\hline 6 & Pousada & 6 & Capela & $\begin{array}{l}\text { Centro } \\
\text { cultural }\end{array}$ \\
\hline 7 & Capela & - & - & - \\
\hline
\end{tabular}

\section{RESULTADOS}

A disponibilidade de uma versão gratuita, a facilidade de manuseio e de aprendizado, além de ampla biblioteca online de modelos, fez com que o SketchUp fosse facilmente integrado às atividades de projetação em ambas as turmas, Ateliê I (2016) e Ateliê Digital Integrado (2017).

Apesar do pouco tempo disponibilizado para o seu aprendizado, os alunos não demonstraram dificuldades na modelagem geométrica dos objetos e conseguiram apresentar suas propostas ao longo das várias etapas do trabalho, desde a apresentação do partido arquitetônico, até do desenvolvimento final do estudo preliminar e do anteprojeto.

Os alunos desenvolveram os partidos arquitetônicos baseados nas pesquisas realizadas online, identificando volumes, sistemas construtivos, materiais, texturas e cores de suas preferências, seguindo na maioria das vezes projetos contemporâneos como referências. Nesse sentido, também utilizando os mesmos métodos descritos por Broadbent (1973) e Rowe (1991), e os mesmos princípios de Mitchell (2010) na construção de formas baseadas em um repertório de formas geométricas. 
Assim, os alunos trabalharam os seus processos criativos inter-relacionando e ordenando dados, verificando os diversos condicionantes, analisando alternativas e desenvolvendo as suas propostas. No entanto, na criação das formas dos diversos objetos foram empregados recursos simples de modelagem, como as operações de varredura e operações boleanas.

A Figura 1 mostra dois estudos realizados na turma Ateliê I (2016) para uma capela. Em (a) a solução foi uma analogia às mãos em situação de louvor, conforme uma analogia de Broadbent (1973) e Rowe (1991), enquanto em (b) a solução recorreu à utilização de formas geométricas triangulares, como descrito por Mitchell (2010).

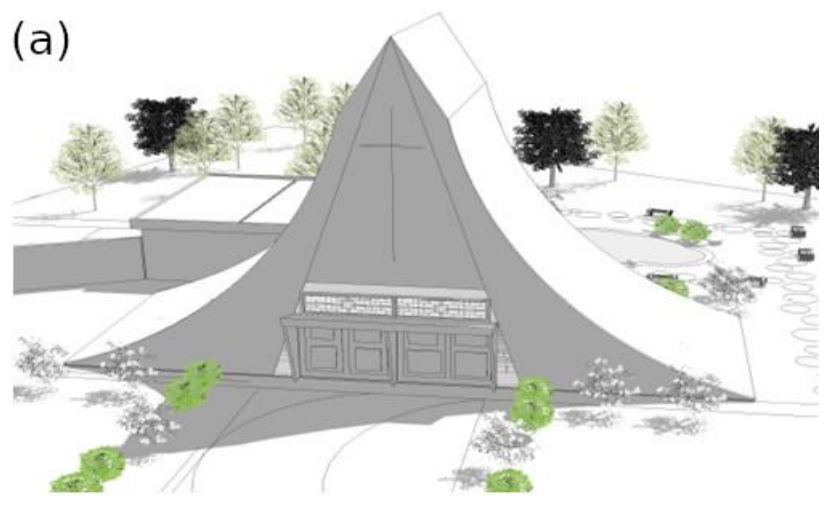

(b)

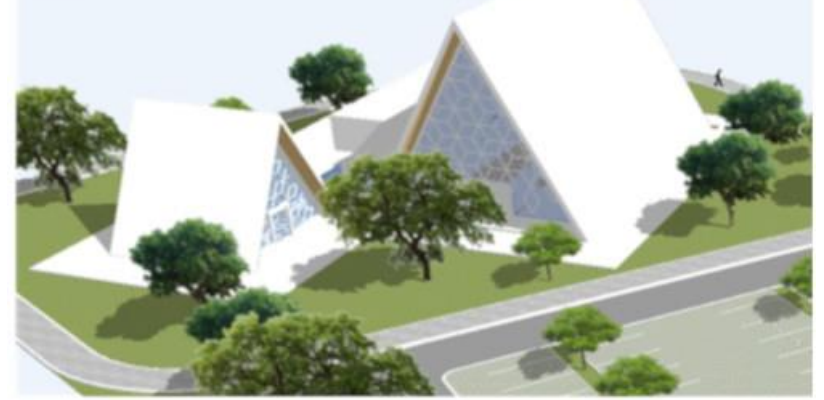

Figura 1: uso de analogia e formas geométricas. Fonte: Autores.

Seguindo análises descritas por Mahfuz (1995), a Figura 2 mostra o resultado da forma de dois estudos, sendo que em (a), o projeto de uma capela é uma organização centralizada, com espaço central dominante, realizada no Ateliê I (2017) e em (b), o estudo para uma escola segue princípios geométricos de organização em formato de eixos coordenados, realizado no Ateliê II (2017).

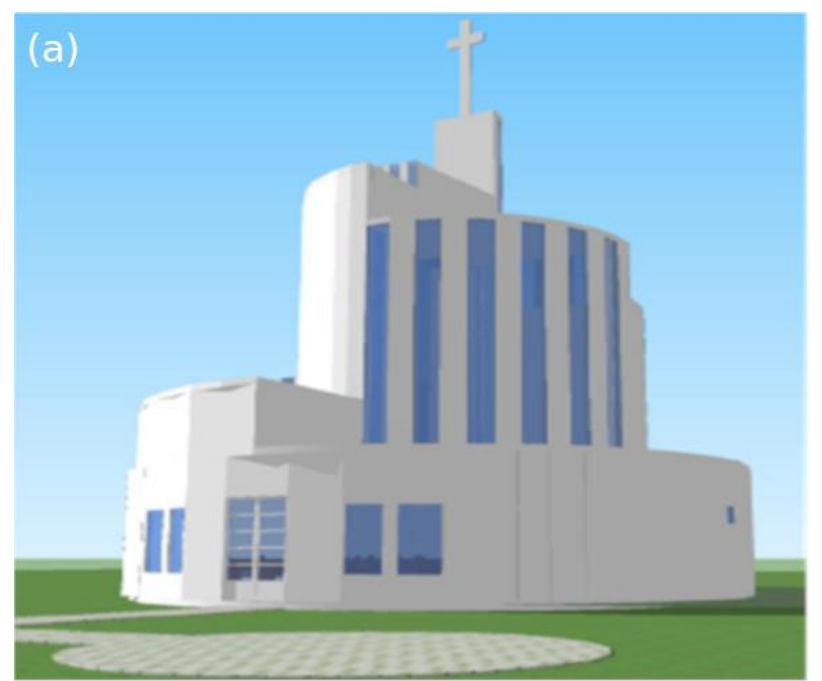

(b)

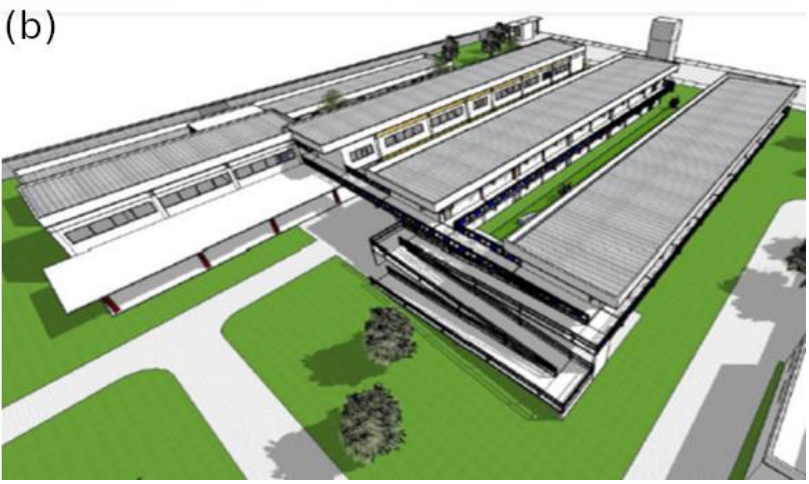

Figura 2: projeto com orientação centralizada e em eixos. Fonte: autores.

No SketchUp o processo de modelagem pode ser trabalhoso quando se pretende explorar formas com superfícies curvas. Nas duas turmas, alguns trabalhos necessitaram do uso de ferramentas com recursos mais sofisticados de modelagem.

No ano de 2016, durante o primeiro exercício projetual, um dos alunos propôs uma barraca de venda de acarajé com cobertura de lona tensionada que, para sua representação, foi necessário o emprego do software Rhinoceros. Esse fato motivou o oferecimento de um curso introdutório sobre o Rhinoceros, realizado durante o recesso letivo de 2016. O curso com quarenta horas foi realizado no LCAD, aberto aos alunos da disciplina e aos demais interessados.

De forma similar, no ano de 2017, durante o segundo exercício projetual, houve a proposta de uma cobertura curva, com sua estrutura composta por vários segmentos extrudados. Analogamente ao ano anterior, realizou-se no recesso letivo, um novo curso introdutório ao Rhinoceros com vinte e quatro horas de duração, para os alunos da disciplina e aos demais interessados.

A Figura 3 mostra o resultado da cobertura da barraca de venda de acarajé (a) e trecho da cobertura do galpão (b): 

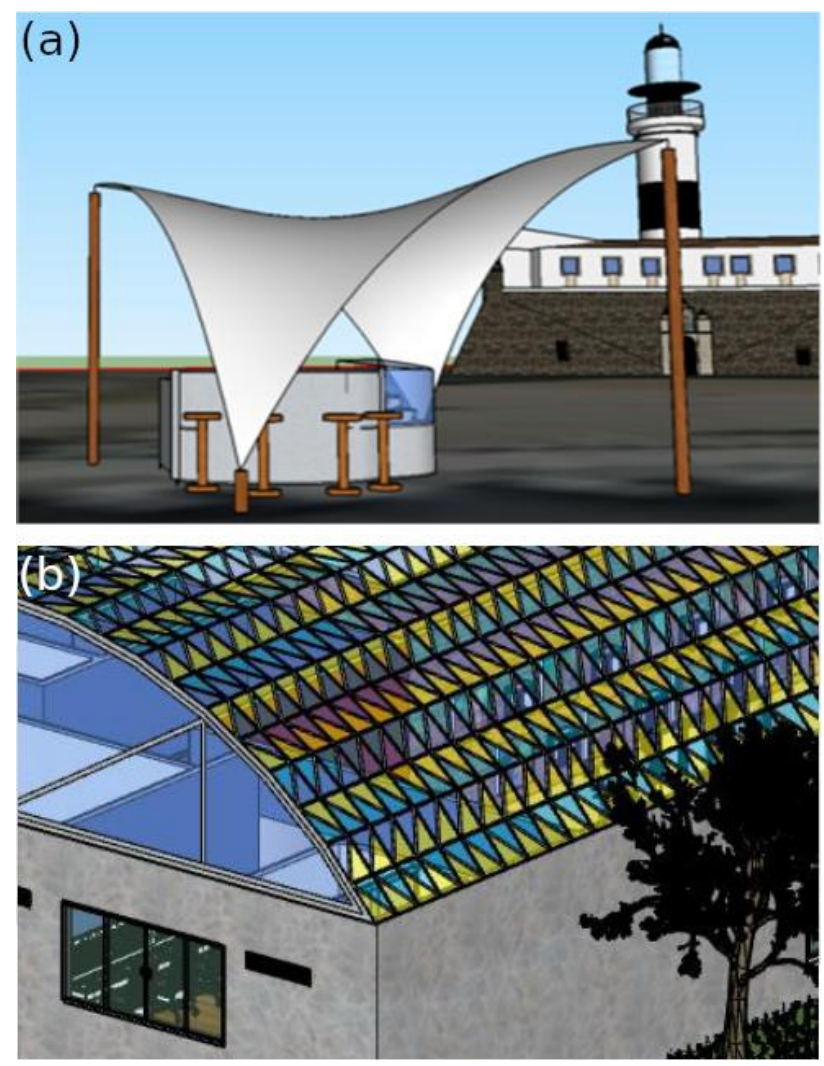

Figura 3: barraca de acarajé e parte da cobertura do galpão. Fonte: Autores.

As duas oficinas de Rhinoceros, tiveram como objetivo principal a apresentação de novos recursos para a projetação, motivando o emprego de formas complexas. Em paralelo, enriquecer o conhecimento dos alunos com exemplos da arquitetura contemporânea.

No curso de 2016, o foco esteve mais voltado à modelagem de superfícies a partir da junção de curvas (Edge Curves), utilizando varredura e operações boleanas. Também foi mostrado o uso do plugin Grasshopper, em aplicações de paneling e diagramas de voronoi. A utilização do Grasshopper teve como objetivo apresentar novos recursos de representação, utilizando linguagem de programação visual e dessa forma oferecer um novo vocabulário gráfico aos alunos, em fase de aprendizado e de descobertas.

Como atividade proposta do curso, foi solicitada uma solução de cobertura e de um painel para a fachada de uma edificação, de forma a complementar um modelo fornecido. Deveriam ser empregados os recursos que fossem julgados adequados ao atendimento da demanda.

A Figura 4 mostra alguns estudos exploratórios para a definição da forma da cobertura (a) e a solução adotada integrada ao volume da edificação (b).
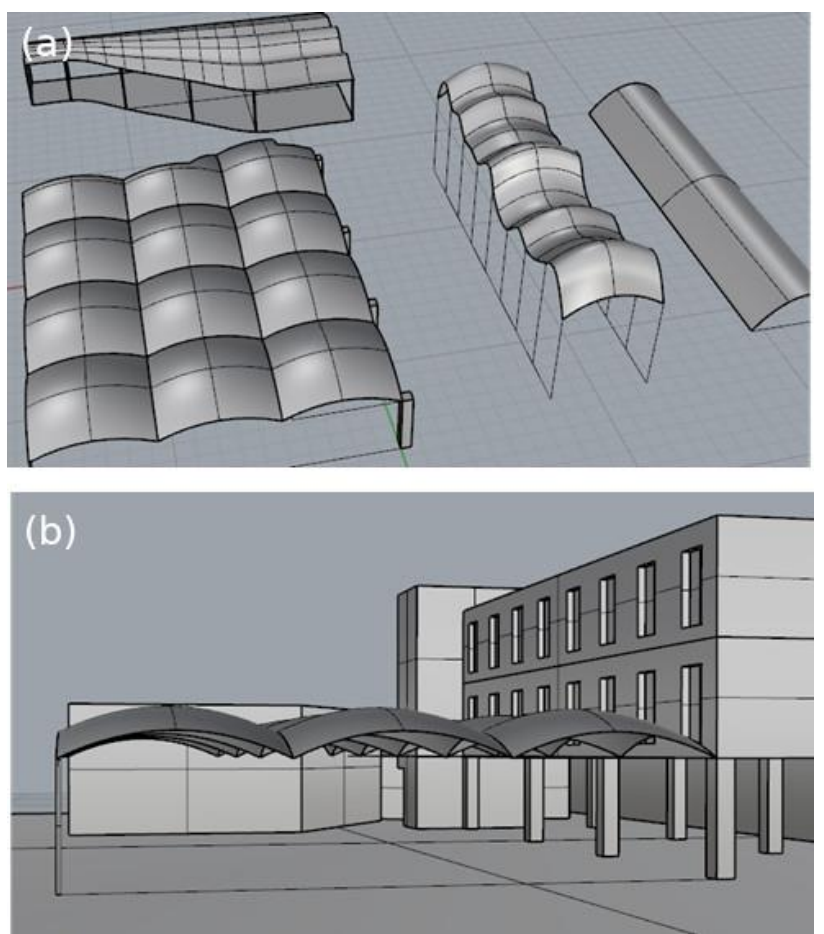

Figura 4: estudos de formas e inserção no modelo. Fonte: Autores.

Na Figura 5 encontra-se o resultado da aplicação de um painel de voronoi (a) e de um paneling (b), na fachada de uma edificação.
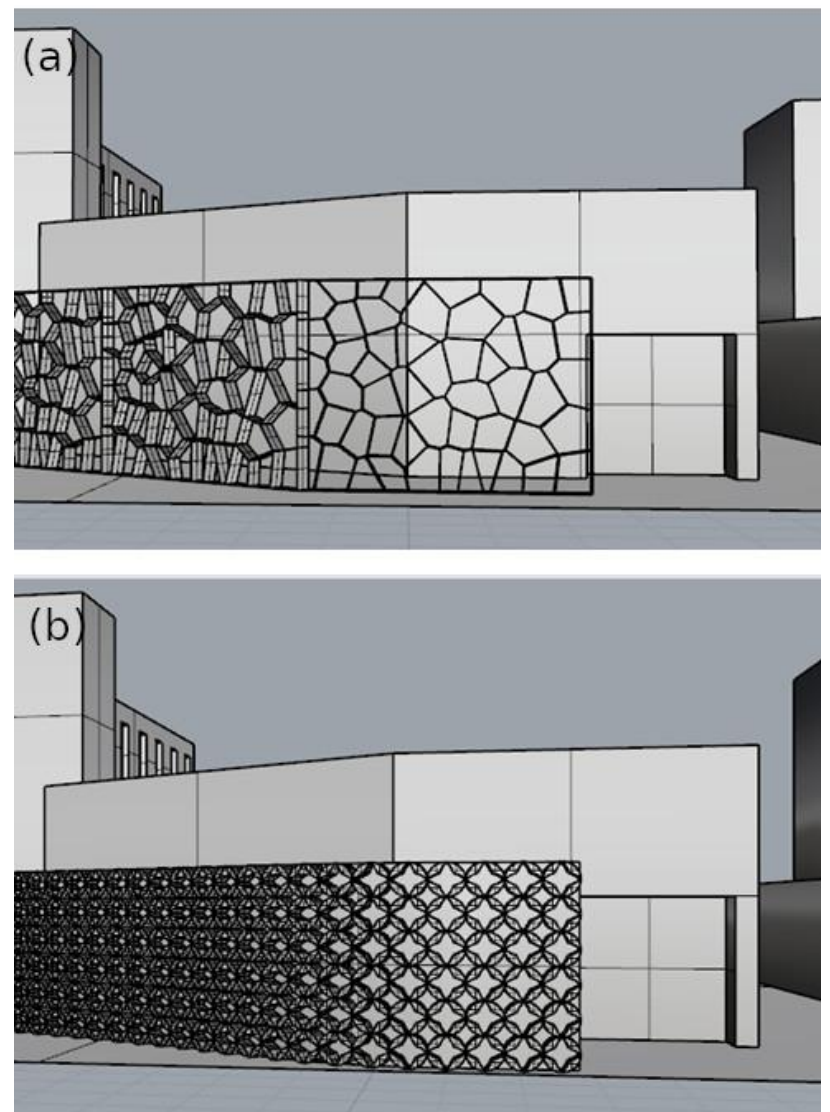

Figura 5: aplicações de "voronoi" e paneling em fachadas. Fonte: Autores.

O curso realizado em 2017 apresentou os mesmos recursos do Rhinoceros e do Grasshopper. Entretanto, acrescentou-se o plugin Lunchbox, como ferramenta para 
a construção de estruturas planas e espaciais para painéis e coberturas. Como exercício prático, foi solicitado o desenvolvimento de uma cobertura treliçada e painéis para fachada de um modelo fornecido.

Num segundo momento, os resultados deveriam ser exportados para o SketchUp. A Figura 6 mostra dois resultados de trabalhos que utilizaram recursos do Rhinoceros, Grasshopper e Lunchbox na modelagem da cobertura, da estrutura e na criação de painéis das fachadas.
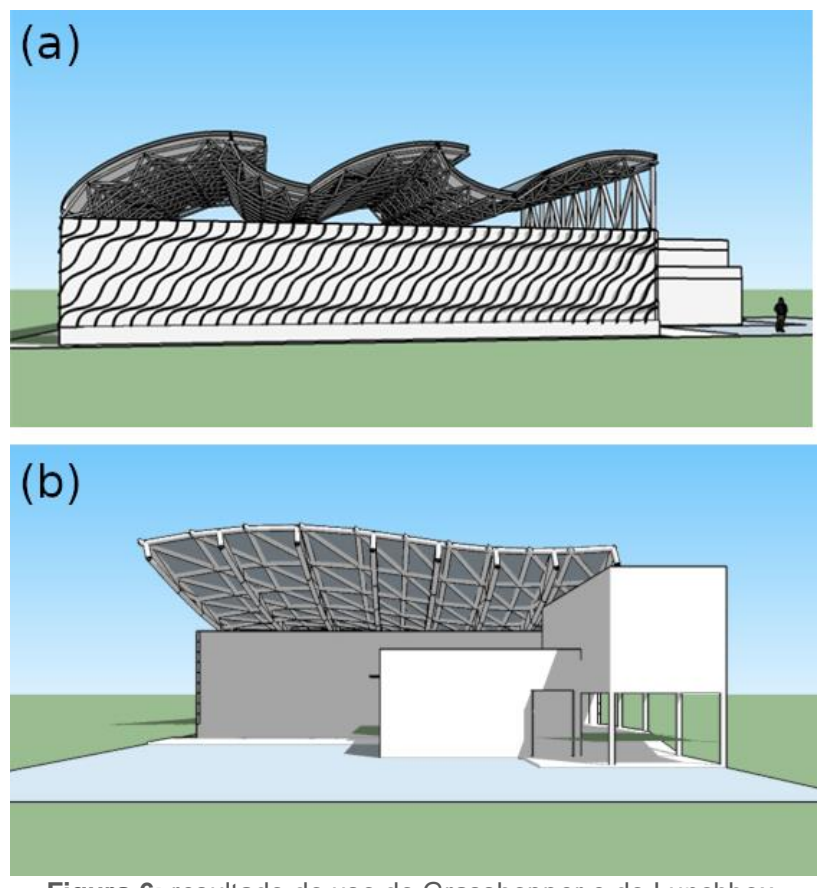

Figura 6: resultado do uso do Grasshopper e do Lunchbox. Fonte: Autores.

Após os dois cursos realizados, verificou-se a apropriação dos novos conhecimentos na realização das atividades seguintes, onde os alunos de modo autônomo, puderam optar pelo uso dos recursos mais convenientes, sempre que a atividade proposta fosse compatível com o uso de tais recursos.

Alguns desses resultados são apresentados na Figura 7, onde são vistos a cobertura de um pátio escolar, realizado no Ateliê II (2017), utilizando triangulação em (a) e um painel decorativo com voronoi, no projeto de uma pousada no Ateliê I (2016) em (b):
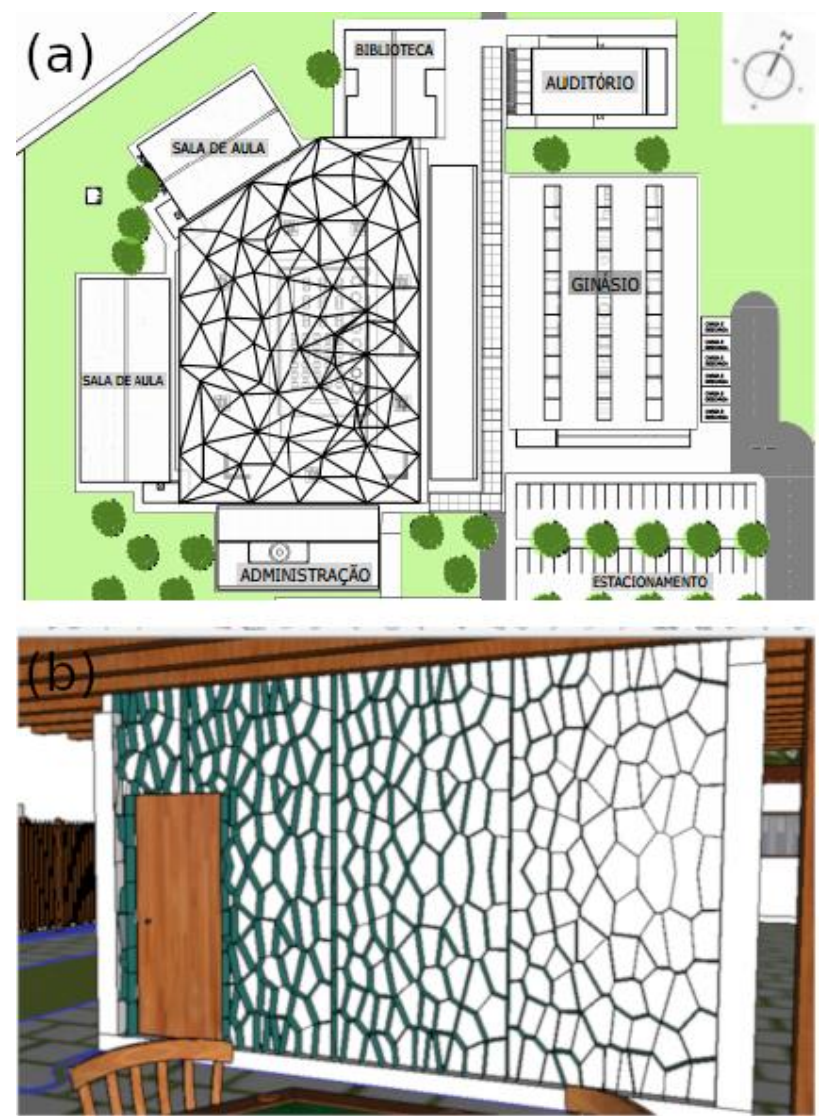

Figura 7: aplicações de recursos do Grasshopper. Fonte: Autores.

Na Figura 8 são mostrados exemplos onde foi utilizada a ferramenta Lunchbox, para a construção (a) das treliças sob a cobertura de um ginásio esportivo, realizado no Ateliê II (2017) e, (b) na casca estrutural de um templo religioso, realizado no Ateliê I (2017).

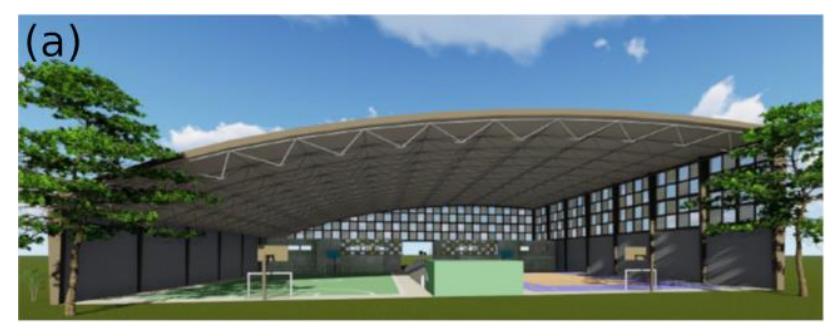

(b)

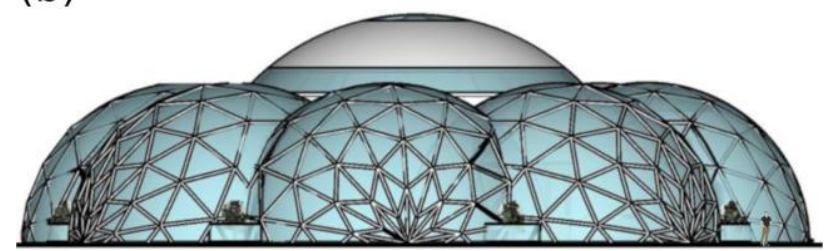

Figura 8: utilização da ferramenta Lunchbox. Fonte: Autores.

Já na Figura 9, são mostrados exemplos onde foi utilizado o Rhinoceros para a definição da volumetria das coberturas e cascas com superfícies curvas, conforme os estudos para as capelas nos Ateliês I de (2016) (a) e (2017) (b) e (c). 

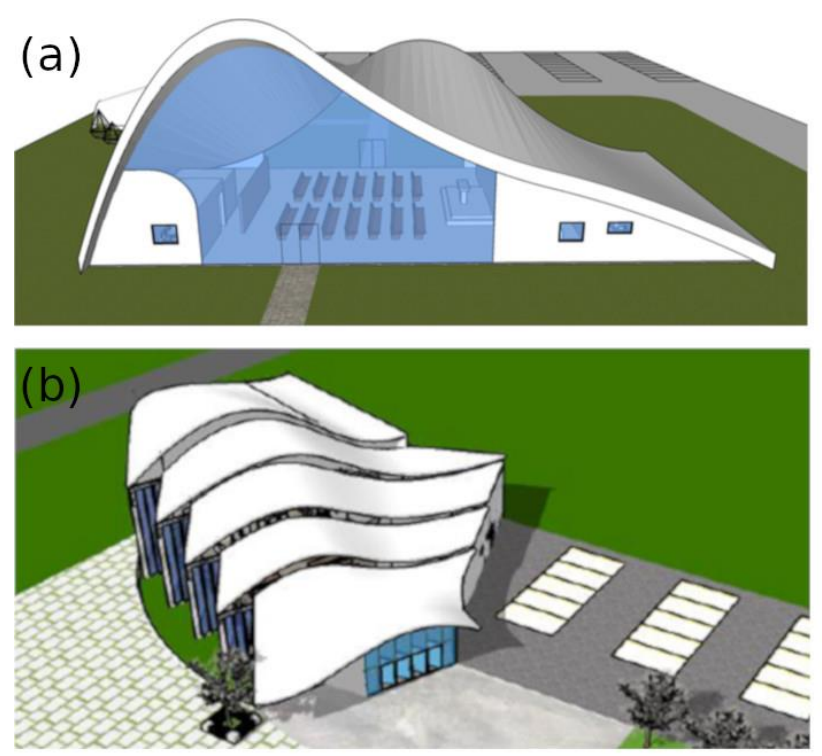

(c)

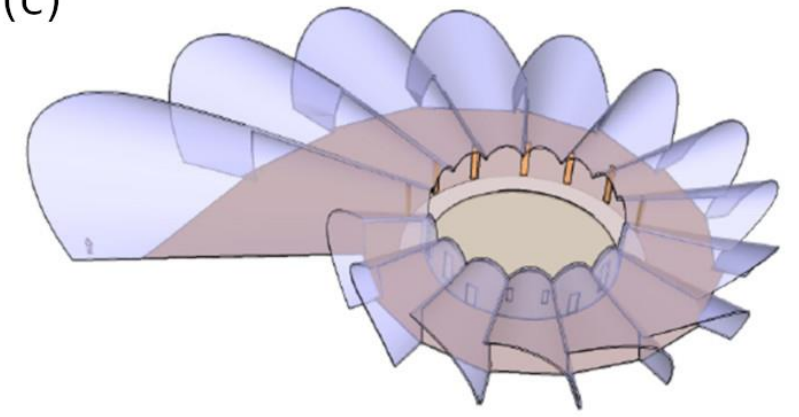

Figura 9: uso de formas complexas na projetação arquitetônica. Fonte: Autores.

Em dois trabalhos, ambos referentes ao projeto da capela do Ateliê I (2016), foram utilizados softwares diferentes, o AutoCAD e Blender 3D. Essas ferramentas não foram discutidas amplamente em sala de aula, mas objetivaram explorar novos recursos com alguns alunos em resposta a demandas específicas deles. Nesses casos, os professores mostraram aos estudantes interessados 0 processo de construção das formas desejadas nesses programas.

Foram construídos um paraboloide hiperbólico representando a superfície da cobertura da capela utilizando o AutoCAD (a), e o detalhe do pilar central e cobertura de um templo religioso (candomblé) modelados no Blender 3D (b). Os resultados são apresentados na Figura 10.
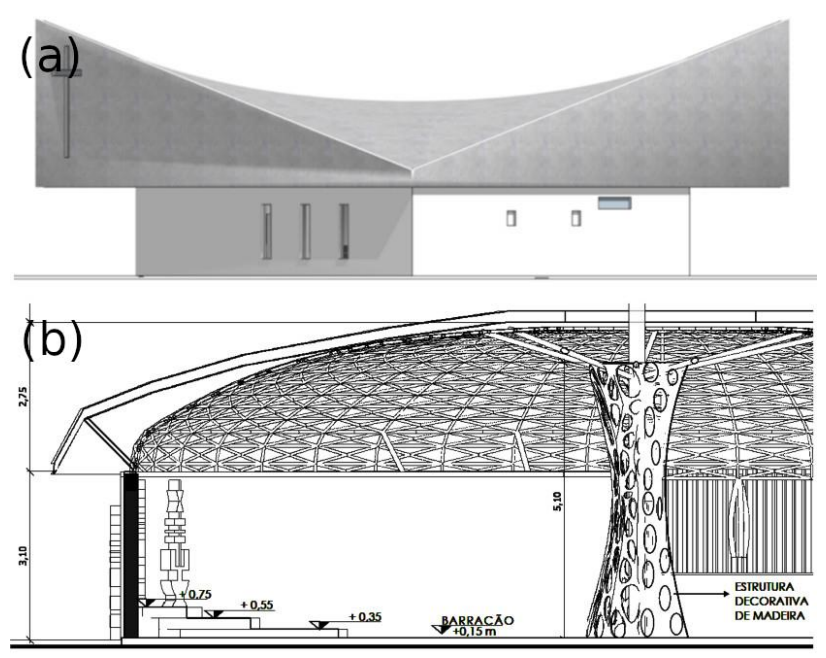

Figura 10: utilização de ferramentas diversas. Fonte: Autores.

\section{DISCUSSÃO}

O uso de recursos computacionais na projetação arquitetônica desde o início das atividades do Ateliê I (2016) e do Ateliê Digital Integrado (2017) trouxe uma boa dinâmica com relação à realização das tarefas, uma vez que os recursos para a pesquisa e o desenvolvimento das atividades estavam centralizados, o que motivou a permanência do grupo de alunos em sala de aula em todas as atividades.

A realização de estudos sobre o tema do projeto, suas restrições, programa de necessidades e outros subsídios inicias, até a concretização da forma puderam ser realizados com 0 auxílio do computador, utilizando diferentes mecanismos de projetação, como os métodos heurísticos e uso de mundos projetuais.

O desenvolvimento dos softwares, a evolução das interfaces, o uso cotidiano de recursos computacionais em diferentes segmentos aproximou o uso da tecnologia à projetação arquitetônica, fazendo com que o seu uso se tornasse acessível, vantajoso e economicamente viável.

A possibilidade de uso de várias ferramentas trouxe aos alunos liberdade e flexibilidade na projetação e essa amplitude de recursos ampliou as possibilidades de soluções formais enriquecendo o processo criativo dos mesmos. As rotinas de uso das ferramentas digitais e seus requisitos, impuseram aos alunos a necessidade de integração de diferentes recursos, técnicas e métodos de trabalho. As limitações encontradas pelos alunos para modelar as formas desejadas foram sendo superadas paulatinamente com o auxílio dos professores e dos monitores. As modelagens mais complexas que foram realizadas com o apoio dos docentes e serviram como novos desafios, pois os processos foram sempre discutidos e compartilhados com todos.

Houve uma preocupação com o processo de desenvolvimento da forma, desde os primeiros estudos até a solução final adotada. Isso porque a metodologia empregada permitiu o acompanhamento das etapas de cada atividade, sempre com o intuito de apoiar e orientar, buscando a transparência da solução e a fundamentação das propostas. Nesse sentido, valorizou-se o processo de 
refinamento da solução proposta, o aprendizado diferenciado dos recursos digitais e as particularidades e demandas individuais dos estudantes.

Por fim, destaca-se a importância dos professores e monitores estarem capacitados na utilização dos recursos digitais para a projetação, sendo que esses precisam estar atentos à evolução constante dos recursos, com a finalidade de explorar melhor suas potencialidades.

\section{CONSIDERAÇÕES FINAIS}

O emprego da metodologia adotada possibilita uma mudança do foco do curso, usualmente pautado na representação gráfica arquitetônica, para as discussões sobre arquitetura e projetação, envolvendo toda a sua materialidade. Isto torna-se possível porque as ferramentas empregadas simplificaram o processo de representação gráfica bidimensional, reduzindo o "trabalho braçal", permitindo aos alunos um tempo adicional para a discussão, análise e refinamento da proposta projetual da edificação.

Outro aspecto essencial no curso foi a disponibilidade de acesso contínuo a web, o que possibilitou a busca por referências diversas, sejam relativas à estética de edificações similares, aspectos formais, sistemas estruturais e construtivos, materiais etc.

Esse conjunto de fatores trouxe dinâmica ao curso e aguçou a curiosidade da maior parte dos alunos para explorar melhor as possibilidades projetuais. Tudo isto contribuiu de forma positiva não só para o domínio das ferramentas empregadas, mas também para uma maior maturidade dos estudantes que participaram dos dois cursos.

É importante frisar ainda que as soluções projetuais estavam em nível de estudos preliminares no caso dos alunos participantes das turmas de Ateliê I e em nível de anteprojeto para os alunos da Ateliê II.
Por fim, é importante declarar que as experiências foram gratificantes e que a maior parte dos alunos participantes ficaram satisfeitos com os resultados que obtiveram ao final do curso.

\section{AGRADECIMENTOS}

À Fundação de Amparo à Pesquisa do Estado do Mato Grosso (FAPEMAT) pela concessão da bolsa de estudo ao primeiro autor.

Aos alunos das turmas de Ateliê 1 e Ateliê 2, dos anos de 2016 e 2017, por suas participações nos cursos e cessão das imagens para a publicação deste artigo.

\section{REFERÊNCIAS}

Bodem, M. A. (org.) Dimensões da criatividade. Porto Alegre: Artmed, 1999.

Broadbent, G. Diseño arquitectónico. Arquitectura y Ciencias Humanas. Barcelona: Gustavo Gili, 1973.

Lawson, B. Como arquitetos e designers pensam. São Paulo: Oficina de textos, 2011.

Maciel, S. D.; Amorim, A. L.; Checcucci, E. S. (2018). Ensino de projeto de arquitetura em ambiente digital: uma experiência na Faculdade de Arquitetura da Universidade Federal da Bahia. Gestão e Tecnologia de Projeto, v. 13, n. 1, p. 21-37. doi: 10.11606/gtp.v13i1.133839

Mahfuz, E. C. Ensaio sobre a razão compositiva. Viçosa: UFV; Belo Horizonte: AP Cultural, 1995.

Mitchell, W. J. A lógica na arquitetura. Campinas: Unicamp, 2011.

Ostrower, F. Criatividade e processos de criação. 30. ed. Petrópolis: Vozes, 2014.

Rowe, P. G. Design Thinking. Massachussets: MIT Press, 1991.

Silva, E. Uma introdução ao projeto arquitetônico. Porto Alegre: UFRGS, 1998. 